\title{
VARIABILIDADE DE LONGO PRAZO DA ABUNDÂNCIA DE JUVENIS DE CAMARÕES-ROSA FARFANTEPENAEUS BRASILIENSIS (LATREILLE, 1817) E F. PAULENSIS (PÉREZ-FARFANTE, 1967) (PENAEOIDEA) NA ENSEADA DE UBATUBA
}

\author{
Perroca, J.F. ${ }^{1,}$; Rodrigues Filho, J.L. ${ }^{2}$; Fransozo, A. ${ }^{3}$ \& Costa, R.C. ${ }^{1}$ \\ ${ }^{1}$ Universidade Estadual Paulista (UNESP), Campus Bauru, Laboratório de Biologia de Camarões Marinhos \\ e de Água Doce (LABCAM). \\ ${ }^{2}$ Universidade do Estado de Santa Catarina (UDESC), Campus Laguna. Laboratório de Ecologia. \\ ${ }^{3}$ Universidade Estadual Paulista (UNESP), Campus Botucatu. Núcleo de Estudos em Biologia, Ecologia \\ e Cultivo de Crustáceos (NEBECC).
}

*Autor correspondente: juliaperroca@gmail.com

\begin{abstract}
Mesmo pouco abundantes Farfantepenaeus brasiliensis e F. paulensis são exploradas comumente no norte de São Paulo devido ao seu valor comercial. A avaliação do estado de conservação destas espécies é difícil de se realizar, pelo fato de ambas serem desembarcadas como camarão rosa, o que gera escassez de dados e impossibilita análises ecológicas fidedignas. Este estudo avaliou as capturas de juvenis destas espécies e suas relações com os fatores ambientais na Enseada de Ubatuba em um intervalo de 22 anos. Arrastos mensais ocorreram de Set/95 a Ago/96, Jan/98 a Dez/99, Jul/01 a Jun/03, Jul/05 a Jun/07, Jul/13 a Jun/14 e Set/16 a Ago/17. Dois fatores (meses e anos) e oito covariáveis foram escolhidas como explicativas das capturas: Pluviosidade, pluviosidade lagged -1, pluviosidade lagged -2, Indice Oscilação Sul (ENOS), salinidade, temperatura da água, matéria orgânica e Phi. Após exploração dos dados, selecionou-se apenas uma variável de pluviosidade (colinearidade) e procedeu-se com a transformação logarítmica de abundância (outliers). A interação entre anos e meses e a significativa autocorrelação temporal determinaram o ajuste de Generalized Additive Models (GAMs) com smothers estacionais (mês) e de tendência (ano) com função de autocorrelação. Na sequência, avaliou-se as covariáveis que compuseram os modelos pelo critério de Akaike. O modelo de $F$. paulensis $\left(\mathrm{R}^{2}=0,55\right)$ indicou interação entre anos e meses $\left(p=6,13 \mathrm{e}^{-11}\right)$, sendo altas capturas registradas em meses do primeiro semestre, com forte influência de anos sob tais padrões mensais. Observou-se alta abundância até 1999 e posterior queda em 200x com recuperação a partir de 2006. As variáveis explicativas de $F$. paulensis foram pluviosidade $(p=0.09)$ e ENOS $(p=0.49)$. No caso de $F$. brasiliensis, o modelo $\left(\mathrm{R}^{2}=0,45\right)$ revelou interação entre anos e meses $(p=$ $4.14 \mathrm{e}^{-06}$ ) e indicou altos valores entre janeiro a maio, com variações anuais marcantes, com queda em 2005, rápida recuperação no ano seguinte e manutenção das capturas subsequentemente. As variáveis explicativas foram Phi $(p=0.01)$ e ENOS ( $p=0.16)$. Tais resultados permitem concluir que as espécies se sobrepuseram e que variaram em função dos anos e da sazonalidade, com tendências de manutenção das populações. No entanto, os distintos graus de dependência com variáveis comuns (ENOS) e a diferença de relação com outras variáveis (chuva e Phi) geraram padrões temporais distintos, indicando um certo grau de assincronia entre as populações.
\end{abstract}

Palavras-chave: recrutamento, ENOS, GAM.

Financiamento: FAPESP \#2017/00826-7. 